Images du travail, travail des images

1 | 2016

Quand les groupes professionnels se mettent en images

\title{
Condamnation
}

\section{Anne Kunvari}

\section{OpenEdition}

\section{Journals}

Édition électronique

URL : http://journals.openedition.org/itti/1394

DOI : 10.4000/itti. 1394

\section{Éditeur}

Université de Poitiers

\section{Référence électronique}

Anne Kunvari, «Condamnation », Images du travail, travail des images [En ligne], 1 | 2016, mis en ligne le 01 février 2016, consulté le 14 avril 2021. URL : http://journals.openedition.org/itti/1394 ; DOI : https:// doi.org/10.4000/itti.1394

Ce document a été généré automatiquement le 14 avril 2021.

Images du travail, travail des images 


\section{Condamnation}

\section{Anne Kunvari}

Image 1

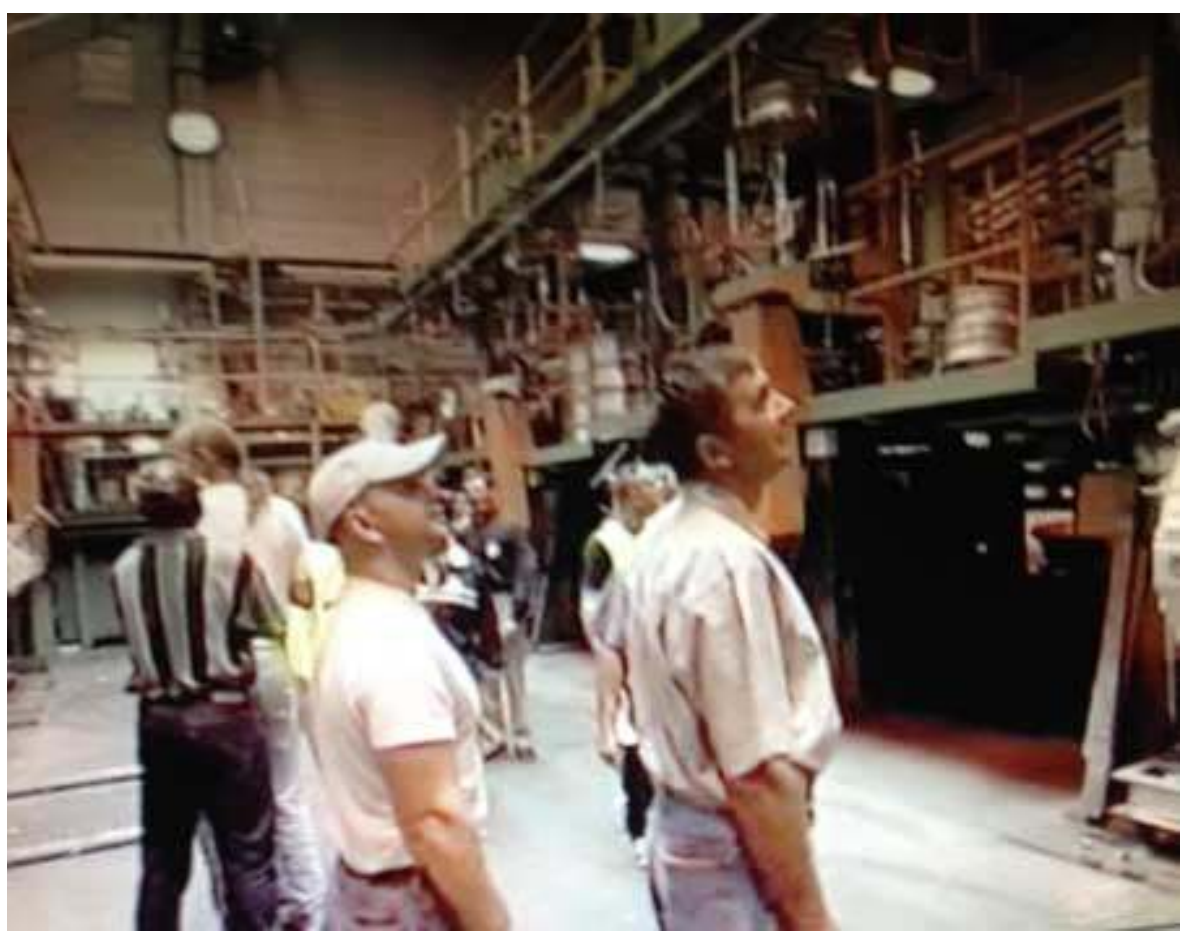

1 Un groupe d'hommes dans une usine observe attentivement une chaine de production. En suivant leur regard, on la découvre très automatisée, visiblement récente. Quelque chose dans la posture désordonnée des hommes indique qu'ils ne sont ni des salariés du lieu ni en formation. Mais alors qui sont-ils et que font-ils dans cette usine? Comment la caméra y est-elle entrée?

2 Cette image est le fruit d'une effraction pacifique. En 2005, je filmais depuis quelques mois le combat des ouvriers d'une usine lorraine contre sa délocalisation en Pologne. Cela deviendra « Mon boulot, l'Europe et moi ». Lors de cette lutte, les ouvriers français 
sont allés rencontrer leurs homologues d'une usine allemande du groupe, pour les sensibiliser et faire pression sur la direction.

Image 2

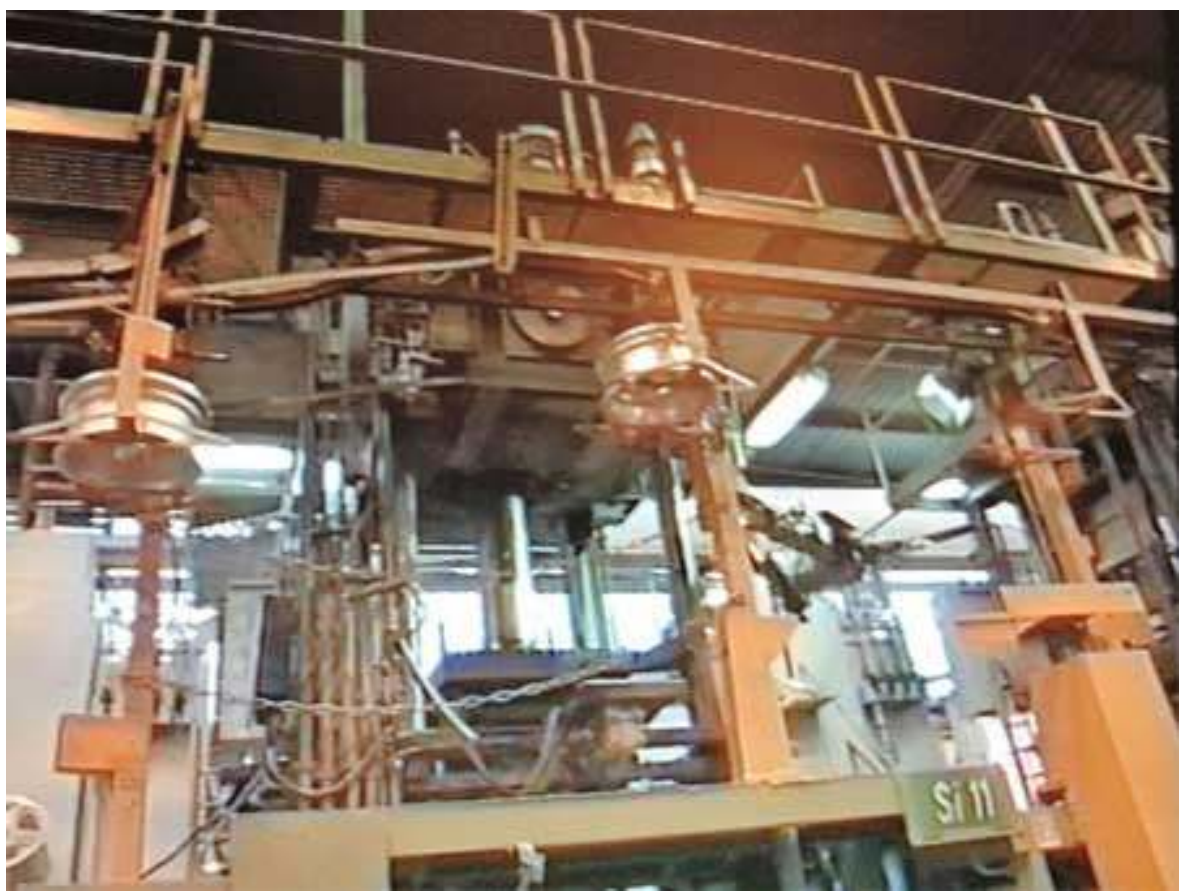

Bien-sûr, le portier de l'usine allemande refuse de les laisser entrer. Ils sautent alors les grilles et pénètrent dans l'enceinte de l'établissement. La caméra les suit. Il y a de l'excitation, du sentiment de " petite » victoire et en même temps de l'inquiétude dans cette cavalcade à travers l'usine interdite. Mais, arrivés devant la chaine centrale de production, les ouvriers s'arrêtent, sidérés et admiratifs. En Lorraine, sur leur site, tout est vieux et non automatisé ; ici, ils découvrent un outil de production moderne, dans lequel des investissements ont été régulièrement effectués. Ils apprécient en connaisseurs la qualité de l'installation et en même temps, un sentiment de révolte les submerge. Je crois qu'ils réalisent à ce moment-là, dans la violence de cette découverte, que le groupe a planifié leur fermeture depuis longtemps. Dans leur dos.

Cette image raconte une trahison.

5 Elle rappelle aussi, en creux, la rareté des images librement filmées dans les entreprises. Propriétés privées, celles-ci excluent toute présence non désirée, adoubée, encadrée. Cette politique de maîtrise de leur image s'avère très efficace : elle limite en nombre et contraint fortement les films sur le travail. Elle nous oblige souvent à trouver des subterfuges ou des formes détournées pour raconter l'univers professionnel. Et puis, il y a des moments de grâce, comme lors du tournage de ce film où, à l'occasion d'un conflit qui se transforme en occupation, nous pouvons filmer en toute liberté. 


\section{AUTEUR}

\section{ANNE KUNVARI}

Auteur-réalisatrice de films documentaires, Anne Kunvari cherche, à travers les histoires individuelles et singulières, à interroger le fonctionnement des systèmes et à en mettre à jour les logiques profondes. Elle s'est beaucoup intéressée au monde du travail : Bénéfice humain (sur les itinéraires croisés de salariés et de la patronne dans une entreprise d'insertion), Mon boulot, l'Europe et moi (sur le combat d'ouvriers face à la délocalisation de leur usine, France 5), Il était une fois le salariat (sur cent ans d'histoire du salariat, France 5), Il était une fois les patrons (sur cent ans d'histoire des patrons, France 5) et Le travail malade du chômage (sur comment le chômage dégrade le travail, Arte), questionnent ainsi l'économie et l'univers professionnels. Avant d'être cinéaste, elle a participé à la création et dirigé le magazine la rue, entreprise d'insertion. 